HERNÁNDEZ, Héctor, "La punibilidad de la colusión (secreta) de precios en el derecho chileno".

Polit. crim. Vol. 7, № 13 (Julio 2012), Art. 4, pp. 147 - 167.

[http://www.politicacriminal.cl/Vol_07/n_13/Vol7N13A4.pdf]

\title{
La punibilidad de la colusión (secreta) de precios en el derecho chileno*
}

\author{
Dr. Héctor Hernández Basualto \\ Profesor de Derecho Penal de la Universidad Diego Portales \\ hector.hernandez@udp.cl
}

\section{Resumen}

El trabajo aborda la cuestión de la posible relevancia jurídico-penal de la conducta de colusión (secreta) de precios entre oferentes de bienes y servicios, a la luz de los artículos 285 y 286 del Código penal. A partir de la amplitud del concepto de "medio fraudulento" que emplea la ley, de la lectura igualmente amplia que siempre ha recibido el mismo en la literatura chilena y de la constatación de que el desplazamiento por especialidad de los tipos del Código bajo la vigencia de los tipos penales de la Ley $\mathrm{N}^{\mathrm{o}} 13.305$ de 1959 y del DL No 211 de 1973, fue, por su propia naturaleza, meramente transitorio, se llega a la conclusión de que los preceptos en cuestión son plenamente aplicables a casos actuales de colusión.

\section{Palabras clave}

Colusión (secreta) de precios, delitos contra la libre competencia

\begin{abstract}
The paper addresses the question whether (secret) price collusion between providers of goods and services is a crime under Arts. 285 and 286 of Chilean Penal Code. The following reasons lead to the conclusion that these provisions are indeed applicable to many current cases of collusion: on the one side, both the statutory notion of "fraudulent means" and its interpretation by Chilean legal doctrine is broad enough to cover those cases and, on the other side, the "displacement" of the general provisions of Chilean Criminal Code by the special provisions of Law Nr 13.305 of 1959 and DL Nr 211 of 1973 was in any case just transitory.
\end{abstract}

\section{Key words}

(Secret) Price Collusion, Antitrust Crimes

\footnotetext{
* Este trabajo tiene su origen y reproduce en buena medida, aunque con modificaciones de distinto orden, un Informe en Derecho evacuado por el autor hacia fines de 2009 a solicitud de la Fiscalía Regional Metropolitana Norte del Ministerio Público. Como es obvio, su contenido representa exclusivamente la opinión científica del autor y no compromete a dicha institución.
} 


\section{HERNÁNDEZ, Héctor, "La punibilidad de la colusión (secreta) de precios en el derecho chileno".}

\section{Introducción.}

Este trabajo versa sobre la posible relevancia jurídico-penal de la colusión de precios, entendiendo específicamente por tal la conducta de oferentes de bienes y servicios al público que secretamente se ponen de acuerdo entre sí sobre los precios que cobrarán por tales bienes o servicios, dando lugar de este modo a un precio distinto del que hubiera resultado de no haber mediado dicho acuerdo, esto es, si hubieran competido entre sí también respecto de la variable precio.

Como se sabe, la cuestión ganó enorme interés con el escándalo que provocó el año 2009 el llamado "caso farmacias", todavía pendiente tanto en sede de libre competencia como en la justicia penal. ${ }^{1}$ En este último contexto, la supresión mediante la Ley $\mathrm{N}^{\mathrm{o}} 19.911$, de 14 de noviembre de 2003, de las disposiciones penales que contenía la legislación especial sobre libre competencia (DL No 211, de 22 de diciembre de 1973) y en las que inequívocamente eran subsumibles entre otros los supuestos de colusión, sugiere sin duda, al menos a primera vista, la actual atipicidad de las conductas en cuestión. La "ágil" reacción de distintos parlamentarios y del gobierno de turno para remediar la situación a través de sendos proyectos de ley con nuevas tipificaciones penales parecería confirmar esa impresión. ${ }^{2}$ Ocurre, sin embargo, que al margen de los vaivenes de la legislación especial sobre la materia, el ordenamiento jurídico-penal chileno contiene disposiciones anteriores al surgimiento de dicha legislación especial que parecían y siguen pareciendo pertinentes a los casos en cuestión, de modo que, suprimidas las disposiciones penales de dicha legislación especial, bien podrían recibir aplicación.

\footnotetext{
${ }^{1}$ Luego de una "guerra de precios" mantenida durante los años 2006 y 2007, las tres principales cadenas farmacéuticas del país habrían acordado, a fines de 2007, ponerle término a la misma y resarcirse de las pérdidas sufridas a consecuencia de ella mediante el aumento coordinado del precio a público de un grupo creciente de medicamentos. Luego de varias denuncias y de la pertinente investigación, con fecha de 9 de diciembre de 2008, la Fiscalía Nacional Económica (en adelante FNE) formula ante el Tribunal de Defensa de la Libre Competencia (en adelante TDLC) un requerimiento por prácticas colusorias contra las tres empresas. En marzo de 2009 una de las requeridas reconoce los hechos y su participación en los mismos, provocando el gran escándalo que ha rodeado el caso. Esta revelación se da en el contexto de un acuerdo conciliatorio con la FNE (que le implicó el pago de 1.350 UTM, la elaboración de un Código de Conducta y la aportación de antecedentes respecto de las prácticas objeto del requerimiento), formalizado con fecha 23 de marzo de 2009 y aprobado por el TDLC con fecha 13 de abril del mismo año. Por sentencia de 31 de enero de 2012 el TDLC condena a las otras dos empresas al pago de una multa de 20.000 UTM cada una. Contra esta sentencia ambas empresas deducen recurso de reclamación para ante la Corte Suprema, encontrándose al momento del cierre definitivo de este trabajo (29 de junio de 2012, hechas las correcciones formales sugeridas en su aceptación) la decisión del máximo tribunal en acuerdo. Véase al respecto la documentación disponible en la página web del TDLC (www.tdlc.cl), bajo el Rol C 184-08. Por su parte, en materia penal, en marzo de 2011 el Ministerio Público formalizó investigación contra 17 ejecutivos, tanto de las tres empresas involucradas como de laboratorios farmacéuticos, en virtud de los arts. 285 y 286 del Código penal. Con posterioridad se procedió a la suspensión condicional del procedimiento respecto de tres ejecutivos. A la fecha se está a la espera del cierre de la investigación.

${ }^{2}$ En particular los Boletines No 6454-07 del Senado (véase la moción de 8 de abril de 2009, p. 2; y el Primer Informe de la Comisión de Constitución, Legislación, Justicia y Reglamento, de 3 de agosto de 2009, especialmente p. 3 y ss.) y No 6438-03 de la Cámara (véase moción de 2 de abril de 2009, p. 1 y s.; el Informe de la Comisión de Economía, Fomento y Desarrollo, de 17 de diciembre de 2009, p. 2 y ss.; y especialmente la Indicación Sustitutiva de la Presidenta de la República, No 479-357, de 10 de junio de 2009, p. 2 y s.).
} 
Polít. crim. Vol. 7, № 13 (Julio 2012), Art. 4, pp. 147 - 167.

[http://www.politicacriminal.cl/Vol_07/n_13/Vol7N13A4.pdf]

En concreto se trata de los artículos 285 y 286 del viejo Código penal, ${ }^{3}$ los que, salvo en lo que concierne a la cuantía de la multa, se mantienen inalterados desde la entrada en vigencia del Código. Su tenor es el siguiente:

"Art. 285. Los que por medios fraudulentos consiguieren alterar el precio natural del trabajo, de los géneros o mercaderías, acciones, rentas públicas o privadas o de cualesquiera otras cosas que fueren objetos de contratación, sufrirán las penas de reclusión menor en sus grados mínimo a medio y multa de seis a diez unidades tributarias mensuales.

“Art. 286. Cuando el fraude expresado en el artículo anterior recayere sobre mantenimientos u otros objetos de primera necesidad, además de las penas que en él se señalan, se impondrá la de comiso de los géneros que fueren objeto del fraude".

En las páginas siguientes se indaga sobre los alcances de estos preceptos, específicamente desde el punto de vista de su capacidad para captar supuestos de colusión de precios. Desde ya se adelanta la conclusión, que con esto pasa a ser tesis: aquí se sostendrá que estas disposiciones son plenamente aplicables a conductas de colusión de precios, por las razones y con los alcances que se pasan a desarrollar. No se pretende, sin embargo, un examen exhaustivo de estas figuras, de ahí que, significativamente, no se abordarán los presupuestos del tipo calificado del art. 286.

\section{La colusión de precios como "medio fraudulento" típico.}

La ley no se refiere específicamente a la colusión de precios, pero no resulta problemático entender que ésta constituye, entre otras posibles, una hipótesis de "medio fraudulento" en los términos de los artículos 285 y 286 , tanto si se entiende que los términos amplísimos de la ley van más allá de las formas tradicionales de "fraude" en nuestra legislación (concretamente, más allá del engaño), como si se adhiere a una lectura más restrictiva que identifique "medio fraudulento" con engaño.

Hay buenas razones para sostener que la ley chilena abraza un concepto amplio y comprensivo de "medio fraudulento" que no se agota en el posible engaño. Al respecto es interesante tener en cuenta que en este punto el derecho chileno se apartó sutil pero significativamente del modelo del Código español de 1850, en el sentido de consagrar un conjunto amplio de medios comisivos. Las disposiciones del modelo peninsular tenidas a la vista por la Comisión Redactora eran los artículos 461 a 463, que rezaban de la siguiente manera:

"Art. 461. Los que se coaligaren con el fin de encarecer o abaratar abusivamente el precio del trabajo o regular sus condiciones, serán castigados, siempre que la coligación hubiere comenzado a ejecutarse, con las penas de arresto mayor y multa de 20 a 100 duros".

"Si la coligación se formare en una población menor de 10.000 almas, las penas serán arresto menor y multa de 15 a 50 duros.

\footnotetext{
${ }^{3}$ En lo sucesivo, artículos sin otra mención corresponden al Código penal chileno.
} 


\begin{abstract}
"Las penas se impondrán en ambos casos en su grado máximo a los jefes y promovedores de la coligación, y a los que para asegurar su éxito emplearen violencias o amenazas, a no ser que ellas mereciesen mayor pena".
\end{abstract}

"Art. 462. Los que esparciendo falsos rumores, o usando de cualquier otro artificio, consiguieren alterar los precios naturales que resultarían de la libre concurrencia en las mercancías, acciones, rentas públicas o privadas, o cualesquiera otras cosas que fueren objeto de contratación, serán castigados con las penas de arresto mayor y multa de 100 a 1000 duros".

"Art. 463. Cuando el fraude expresado en el artículo anterior recayere sobre mantenimientos u otros objetos de primera necesidad, además de las penas señaladas en el mismo, se impondrá la del comiso de los géneros que fueren objeto del fraude.

"Para la imposición de estas penas bastará que la coligación haya comenzado a ejecutarse".

Como se ve, en estos artículos el modelo español abordaba dos cuestiones diferentes. La primera, tratada en el art. 461, era la de las "coligaciones" en el ámbito laboral, estimándose como delito, en palabras de Pacheco, "toda coligación, sea de empresarios, sea de operarios, para forzar en un sentido o en otro el curso libre del trabajo y su precio natural"4. Tanto de los comentarios del mismo autor como de sus concordancias con el Código francés (artículos 414 a 416) parece claro que este tema ostentaba un status político especial, porque lo que en definitiva estaba en discusión, más que el correcto funcionamiento del comercio, era el derecho y la libertad de asociación, concretamente, el derecho a la organización y a la lucha sindical (sin perjuicio de que también se mencionara, en un plan de igualdad, la organización patronal), como se desprende por lo demás de la calificación por jefatura prevista en el inciso tercero y que recuerda nítidamente las calificaciones en materia de asociaciones ilícitas.

Por su parte, en los artículos 462 y 463 se abordaba una cuestión específicamente atingente al comercio, como era la alteración del precio natural (el que resultaría "de la libre concurrencia") de las mercancías o cualquier otro objeto susceptible de contratación mediante "artificios" que no se especificaban mayormente, a excepción de la referencia explícita al esparcimiento de rumores falsos (en el art. 462) y, en lo que resulta especialmente relevante para este trabajo, a las coligaciones (en el inciso segundo del art. 463 , referido como todo ese artículo al "fraude" del artículo anterior). De esto se desprende una doble posición de los acuerdos entre oferentes en el modelo español: por una parte como núcleo de una conducta específica con claro sentido político, por la otra como una de las posibles especies de artificio mediante las cuales se podía alterar el precio natural de las cosas.

Pues bien, en un primer momento la Comisión Redactora del Código chileno aprobó la incorporación de los tres artículos, con cambios menores de redacción y penalidad, como

\footnotetext{
${ }^{4}$ PACHECO, Joaquín Francisco, El Código penal concordado y comentado, $4^{\circ}$ edición, Madrid: Imprenta de Manuel Tello, 1870, T. III, p. 385.
} 
Polít. crim. Vol. 7, № 13 (Julio 2012), Art. 4, pp. 147 - 167.

[http://www.politicacriminal.cl/Vol_07/n_13/Vol7N13A4.pdf]

artículos 275 a 277 (sesión 61, de 13 de octubre de 1871), aunque ya con una mutación fundamental, de cuyas razones no ha quedado ningún registro, en el art. 276 (actual art. 285), consistente en que se prescindiera de la referencia a la difusión de rumores falsos como principal medio de comisión en favor de una fórmula genérica que ya no habla del uso de "artificios" sino del empleo de "medios fraudulentos". La importancia del cambio radica en que, cualesquiera que hubiesen sido las razones subyacentes, al prescindirse de un ejemplo tan específico de medio fraudulento y, consiguientemente, de su potencial efecto heurístico restrictivo, la interpretación del artículo quedaba abierta para una enorme gama de posibilidades, que es precisamente, como se verá, lo que ha marcado luego la inteligencia del precepto.

Es en este contexto en el que se inserta la supresión del art. 275 (equivalente al art. 461 del Código español) durante la "Revisación" del proyecto. En esa oportunidad (sesión 156, de 17 de junio de 1873) el comisionado Gandarillas concitó el acuerdo de la Comisión al señalar que no creía justa la subsistencia de dicho artículo

"porque no es posible castigar el uso lejítimo de un derecho, como es el que cada cual tiene para determinar el precio de su trabajo. En esta materia no debe admitirse otro regulador ni correctivo que la misma libertad de industria, de la cual solamente puede resultar una fijación equitativa de los valores. Lo único que merece castigo es el empleo de medios fraudulentos para abaratar o encarecer el precio del trabajo. Para plantear esta idea propuso se suprimiera el art. 276 citado, i que en el siguiente se agregara el trabajo a la enumeración de los objetos cuyo precio fraudulentamente alterado debe penarse". 6

A primera vista alguien podría colegir de esta supresión una decisión general contra la punición de los acuerdos de precios en la actividad comercial, pero eso implicaría pasar por alto el objeto preciso y el status peculiar de lo tratado en el artículo suprimido, referido exclusivamente a la libertad de asociación, tanto sindical como patronal, y su influencia en el precio de un factor económico específico, como era el trabajo. Nada dice sobre la alteración del precio natural de otros factores económicos a través de medio fraudulentos, entre los cuales, conforme a la deliberada amplitud de los términos del art. 276 (actual art. 285), era perfectamente posible subsumir el resto de los acuerdos de precios entre oferentes. Debe recordarse que esto venía explícitamente confirmado por el art. 419 del Código francés, concordancia reconocida del art. 462 español y, junto con éste, muy probable fuente, a través de los comentarios de Pacheco, del cambio de redacción del que llegaría a ser nuestro art. 285 (nótese la referencia a los "géneros" y a los "medios fraudulentos"), en lo pertinente del siguiente tenor:

"Art. 419. El que por hechos falsos o calumniosos divulgados intencionalmente entre el público, por medio de ofertas hechas a los mismos vendedores, por la reunión o coligación entre los principales tenedores de una misma mercancía o artículo, formada para no venderla, o venderla sólo a cierto precio, o por otras vías o medios fraudulentos, hicieren subir o bajar el precio de géneros, mercancías, documentos o

\footnotetext{
${ }^{5}$ Cfr. Actas de las sesiones de la Comisión Redactora del Código penal chileno, Santiago: Imprenta de la República de Jacinto Núñez, 1873, p. 120.

${ }^{6}$ Actas, cit. nota ${ }^{\circ}$ 5, p. 280.
} 


\section{HERNÁNDEZ, Héctor, "La punibilidad de la colusión (secreta) de precios en el derecho chileno".}

efectos públicos, en más o menos suma de la que hubiere resultado de la libre y natural concurrencia del comercio, será castigado con las penas...".

Así, es interesante hacer notar que Fuensalida, el que más atención le presta a la supresión del art. 275 (art. 461 del Código español) de entre los primeros comentaristas del Código, no extrae ninguna conclusión general sobre los acuerdos contrarios a la formación de los precios conforme a la libre competencia y más bien se limita a confirmar la situación particular de las organizaciones de obreros y operarios:

"Se sigue que el artículo comprende a los que pagan los salarios del trabajo, a los obreros i trabajadores que los reciben, a los tenedores de las especies susceptibles de contratación i a los interesados en comprar dichas especies por un precio más bajo del que resulta de la competencia del comercio libre. Se sigue también que en Chile no se penan las simples coligaciones de los fabricantes, maestros, agricultores i demás personas que trabajan con jente asalariada, aunque tengan por objeto operar una baja irregular i forzada en los salarios; ni las coligaciones de obreros i demás hombres de salarios para no trabajar sino por un precio más subido que el actual: unos i otros usan de su libertad, según las palabras del acta citada, i mientras no ofendan derechos ajenos garantidos con una sanción penal no deben ser castigados". 7

A lo que agrega, en plena consonancia con lo que se viene diciendo, que "por lo demás, el art. 419 del Código Penal de Francia nos suministra ejemplos de medios fraudulentos que pueden usarse para hacer subir o bajar el precio natural de los salarios, jéneros, mercadería, etc.", 8 entre los que se contaban precisamente los acuerdos de precios.

Esta comprensión amplia de los "medios fraudulentos" típicos es una constante en la literatura jurídico-penal chilena. ${ }^{9}$ Así, siempre entre los primeros comentaristas, mientras

7 FUENSALIDA, Alejandro, Concordancias i comentarios del Código penal chileno, Lima: Imprenta comercial, 1883, T. II, p. 301.

${ }^{8}$ FUENSALIDA, Concordancias, cit. nota $n^{\circ} 6$, p. 301.

${ }^{9}$ En la literatura española se aprecia una visión más restrictiva, sin duda asociada a los términos más específicos de su texto legal, que ya en sus orígenes, sin perjuicio de la cláusula genérica del uso "de cualquier otro artificio", se centraba nítidamente, como se ha visto, en la difusión de rumores falsos. La redacción del Código de 1850 se mantuvo inalterada hasta la Ley de 15 de noviembre de 1971 (como art. 540), ocasión en que, además de transformarse en delito de mera actividad (que reprime ahora a los que "intentaren alterar los precios"), recoge como medios comisivos, junto a la ya conocida difusión de "noticias falsas o tendenciosas" y el uso genérico de "cualquier otra maquinación", el empleo de "violencia, amenaza o engaño" (cabe hacer presente, en todo caso, que con la incorporación expresa de la hipótesis de "engaño" queda de manifiesto que esa hipótesis específica no agota el significado de los antiguos "artificios" ni de las nuevas "maquinaciones", fórmulas que necesariamente tienen un alcance más amplio). Finalmente, con el Código de 1995 se suprime (en el art. 284) la referencia genérica a cualquier otra maquinación y el tipo queda circunscrito taxativamente a las hipótesis de difusión de noticias falsas, empleo de violencia, amenaza o engaño, o utilización de información privilegiada. Es este último aspecto el que marca la diferencia más significativa entre el derecho chileno y el peninsular: mientras entre nosotros el tipo se construyó y se ha mantenido como una fórmula genérica de alteración fraudulenta del precio natural de los productos y servicios, en España se ha profundizado la tendencia hacia una enumeración de casos específicos de fraude, que ha concluido con un catálogo cerrado. Al margen de cualquier valoración, se trata sin duda de un camino diverso al transitado por el derecho chileno, razón por la cual en esta materia las opiniones de los autores peninsulares deben considerarse con importantes reservas en nuestro debate jurídico-penal. Por lo mismo, salvo para cuestiones puntuales, este trabajo no se hace cargo mayormente de esa vertiente. 
Polít. crim. Vol. 7, № 13 (Julio 2012), Art. 4, pp. 147 - 167.

[http://www.politicacriminal.cl/Vol_07/n_13/Vol7N13A4.pdf]

Pedro Javier Fernández se centraba fundamentalmente en la difusión de noticias falsas o tendenciosas en la línea del art. 462 del Código español, ${ }^{10}$ Robustiano Vera insistía en considerar típicas, contra la historia fidedigna del establecimiento de la ley, las coaligaciones de empresarios o de operarios al modo del art. 461 de dicho Código, sin perjuicio de hacer mención de posibles avisos falsos, ${ }^{11}$ en tanto que Bañados Espinosa ponía exclusivamente como ejemplo de los casos cubiertos por el tipo las prácticas contrarias a la libre competencia, los llamados trusts, ${ }^{12}$ que son precisamente las conductas que interesan en este trabajo.

En tiempos más recientes esa comprensión amplia se mantiene y consolida. Así se expresaba al respecto Del Río:

"La frase generalísima 'medios fraudulentos', empleada por el legislador, comprende todos los medios conducentes a las resultantes previstas por la ley, y da al tribunal las facultades necesarias para aplicar la sanción a todos los casos concretos que se presenten en la práctica, con bastante amplitud.

"Por fraudulento debe entenderse todo procedimiento engañoso o falaz. Quedan incluidas en estos medios las maquinaciones capaces de turbar las condiciones normales de un mercado, impidiendo la regulación automática de los valores por la ley de la oferta y la demanda y obteniendo una regulación ficticia por medio de ofertas y demandas irreales". ${ }^{13}$

Y especialmente Labatut, quien ilustrando aún más la amplitud de los posibles medios típicos ponía como ejemplo idóneo el acaparamiento de mercaderías:

"Persigue esta disposición, basada en la libertad de contratación, la finalidad de asegurar el libre juego de la oferta y de la demanda, e impedir las alzas o bajas injustificadas del precio de la mano de obra y de las cosas comerciables... Los medios fraudulentos pueden consistir en la difusión de rumores o noticias falsos, en el acaparamiento anormal de determinadas mercaderías, etc.". ${ }^{14}$

Etcheberry, por último, más incluso que Del Río, pone especial énfasis en las formas de engaño, tomando como ejemplo la difusión de rumores falsos en la línea del modelo histórico español, ${ }^{15}$ pero luego amplía notablemente su mirada cuando en el mismo contexto trata las prohibiciones de los artículos 52 y 53 de la Ley de Mercado de Valores

\footnotetext{
${ }^{10}$ FERNÁNDEZ, Pedro Javier, Código penal de la República de Chile esplicado y concordado, $2^{\circ}$ edición, T. II, Santiago: Imprenta Barcelona, 1900, pp. 34 y ss., con largo tratamiento del célebre caso en que habría estado envuelto en Londres Lord Cochrane antes de viajar a América.

${ }^{11}$ VERA, Robustiano, Código penal de la República de Chile comentado, Santiago: Imprenta de P. Cadot, 1883 , pp. 483 y ss.

12 BAÑADOS ESPINOSA, Florencio, Código penal de la República de Chile concordado y comentado, Santiago: L.A. Lagunas, 1920, p. 238, comentando el caso de un comerciante francés linchado por hacer subir el precio del azúcar a niveles exorbitantes.

${ }^{13}$ DEL RÍO, J. Raimundo, Derecho penal, Santiago: Nascimento, 1935, T. III, p. 242.

${ }^{14}$ LABATUT, Gustavo, Derecho penal, T. II, $7^{\circ}$ edición (a cargo de Julio ZENTENO), Santiago: Editorial Jurídica de Chile, 1983, p. 107.

${ }^{15}$ ETCHEBERRY, Alfredo, Derecho penal, $3^{\circ}$ edición, Santiago: Editorial Jurídica de Chile, 1998, T. IV, p. 280.
} 
(en adelante LMV) ${ }^{16}$ y las considera lex specialis tratándose de valores, ${ }^{17}$ en circunstancias que manifiestamente se trata de previsiones que van más allá de los límites estrictos del engaño.

Todo indica entonces que en este contexto la ley emplea la noción de "medios fraudulentos" en términos amplios que exceden largamente del concepto de engaño, lo que se ve confirmado de modo inequívoco por el último artículo del párrafo, el art. 287, donde se reprime a quienes "emplearen amenaza o cualquier otro medio fraudulento para alejar a los postores en una subasta pública con el fin de alterar el precio del remate", mostrando así que el legislador considera la amenaza como posible medio fraudulento, en concordancia, además, con el final del mismo artículo, donde se expresa que en rigor se trata simplemente del empleo de "medios ilícitos" ("a no merecer mayor pena por la amenaza u otro medio ilícito que emplearen"). ${ }^{18}$

Puede sostenerse entonces, de la mano de la comprensión tradicional de nuestra doctrina, que el art. 285 constituye un tipo genérico de atentado contra la libre competencia como factor determinante de la formación de precios en la economía, caracterizado por el empleo para ese fin de unos "medios fraudulentos" cuyo sentido y alcance, si bien no se opone ni excluye el contenido tradicional de los llamados fraudes por engaño, sí lo excede y se identifica en general con el empleo de medios ilícitos. En ese contexto, pocas dudas pueden caber sobre la posibilidad de subsumir en él la colusión de precios, que reconocidamente constituye la forma más elemental de falsificar la competencia.

Ahora bien, aun si se asumiera, contra lo que se viene diciendo, que bajo la expresión "medios fraudulentos" el art. 285 exige alguna forma de engaño, eso sólo excluiría la tipicidad de los acuerdos de precios abiertos, pero no de la colusión en los términos en que ha sido definida en este trabajo, porque en el caso de un acuerdo secreto de precios entre oferentes que supuestamente son competidores, el engaño es manifiesto. ${ }^{19}$ En efecto, la colusión de precios satisface a la perfección las exigencias que la literatura especializada le impone al llamado engaño concluyente, esto es, simplificando al máximo, de casos en que

\footnotetext{
${ }^{16}$ Art. 52 inciso primero LMV: "Es contrario a la presente ley efectuar transacciones en valores con el objeto de estabilizar, fijar o hacer variar artificialmente los precios". Art. 53 incisos primero y segundo LMV: "Es contrario a la presente ley efectuar cotizaciones o transacciones ficticias respecto de cualquier valor, ya sea que las transacciones se lleven a cabo en el mercado de valores o a través de negociaciones privadas". "Ninguna persona podrá efectuar transacciones o inducir o intentar inducir a la compra o venta de valores, regidos o no por esta ley, por medio de cualquier acto, práctica, mecanismo o artificio engañoso o fraudulento".

${ }^{17}$ ETCHEBERRY, Derecho penal, cit. nota ${ }^{\circ} 14$, p. 280.

${ }^{18}$ En el mismo sentido MERA, Jorge, Fraude civil y penal. El delito de entrega fraudulenta, $2^{\circ}$ edición, Santiago: ConoSur, 1994, p. 90. En esto yerra rotundamente la sentencia de la Corte de Valparaíso de 23 de marzo de 1929, Gaceta de los Tribunales 1929-I, sentencia 86, pp. 428, 433, cuando equipara sin mayor fundamento los "medios fraudulentos" con el engaño.

${ }^{19}$ En este punto fracasaría irremediablemente una lectura histórica que pretendiera que la supresión del delito de coligación en materia laboral tuvo un alcance no circunscrito a esa materia e implicó la validación indiferenciada de todos los acuerdos de precios, porque aun con una lectura restrictiva del concepto de fraude, un acuerdo engañoso es sin duda un acuerdo fraudulento, y el legislador fue enfático en sostener su repudio general hacia los medios fraudulentos. En consecuencia, a lo más que podría aspirar esa tesis es a la atipicidad de los acuerdos de precios abiertamente reconocidos, pero no de la colusión.
} 
lo declarado expresamente se ve contradicho lógica, empírica o normativamente por la ausencia de una circunstancia que, en cuanto presupuesto del sentido de la declaración, se entiende implícita en ella sin necesidad de mención expresa. ${ }^{20}$ Porque sin duda en las ofertas de bienes y servicios al público en el contexto de un modelo económico basado en la libre competencia, ${ }^{21}$ va implícita la declaración de que el precio exigido corresponde a los cálculos y posibilidades individuales de un oferente que actúa bajo condiciones efectivas de competencia relativa. ${ }^{22}$

Esto se ha reconocido ampliamente en la doctrina y jurisprudencia comparada, especialmente en la alemana, respecto de las ofertas que se hacen en el contexto de licitaciones o subastas, en el sentido de que dichas ofertas llevan implícita la declaración de no obedecer a acuerdos secretos entre los participantes en la licitación o subasta, dando así lugar en algunos casos de acuerdos de precios entre competidores incluso a condenas a título de estafa (Submissionsbetrug). ${ }^{23}$ Lo mismo debe regir, y por idénticas razones, para las ofertas que se dirigen al público en general. Si no se ha profundizado mayormente sobre este punto no es porque existan dudas respecto de la concurrencia de engaño, sino exclusivamente por las dificultades que en sede de estafa ofrece la determinación del perjuicio patrimonial que dicho tipo exige, ${ }^{24}$ y que es lo que en definitiva ha llevado a que el legislador alemán haya introducido en 1997 un tipo específico de "fraude de licitaciones" en el Código penal ( $\$ 298 \mathrm{StGB}$ ), sin exigencia de perjuicio patrimonial y en el ámbito sistemático de los delitos contra la libre competencia, delito que, sin embargo, según opinión mayoritaria, se encuentra en potencial relación de concurso ideal con la estafa, ${ }^{25}$ precisamente porque en el caso concreto pueden verificarse también los requisitos de esta última figura. En el caso de las ofertas al público las dificultades de aplicación del tipo de estafa aumentan, por la ausencia de un contexto negocial que permita concretar la relación intersubjetiva propia del delito, lo que también lleva al establecimiento de tipos especiales

\footnotetext{
${ }^{20}$ Al respecto, entre muchos otros, KINDHÄUSER, Urs, “§ 263”, en: KINDHÄUSER, Urs et al (editores), Nomos-Kommentar zum Strafgesetzbuch, $2^{\circ}$ edición, Baden-Baden: Nomos, 2005, $\mathrm{N}^{\mathrm{o}}$ marginal 110; HEFENDEHL, Roland, “§ 263”, en: AA. VV., Münchener Kommentar zum Strafgesetzbuch, München: Beck, 2006, T. IV, No marginal 90 y ss.; FRISCH, Wolfgang, “Konkludentes Täuschen”, en: PAWLIK, Michael et al (editores), Festschrift für Günther Jakobs, Köln etc.: Heymanns, 2007, pp. 97-130, pp. 104 y ss. Para el derecho chileno HERNÁNDEZ, Héctor, "Aproximación a la problemática de la estafa", en AA. VV., Problemas actuales de Derecho penal, Temuco: Universidad Católica de Temuco, 2003, pp. 147-190, p. 164 y s.; MAÑALICH, Juan Pablo, “¿Responsabilidad jurídico-penal por causaciones de menoscabo patrimonial a propósito de fallas en la construcción de inmuebles?”, Política Criminal, Vol. 5 No 10 (2010), pp. 341-351, pp. 345 y ss.

${ }^{21}$ Hoy esto es evidente, sobre todo a la luz de una legislación especial en materia de libre competencia, pero lo era también en la época de promulgación del Código, aunque no existiera tal legislación especial. En todo caso, aunque esto último fuera disputado, la conclusión sería la misma, porque el concepto de engaño es uno que se adapta al significado social de las conductas en el tiempo en que se despliegan.

${ }^{22}$ Así HEFENDEHL, “\$ 263”, cit. nota $\mathrm{N}^{\circ} 19, \mathrm{~N}^{\mathrm{o}}$ marginal 96, quien habla, con referencia a la legislación antimonopolios, de "preconfiguración normativa del contenido de la declaración".

${ }^{23}$ Al respecto, por todos, TIEDEMANN, Klaus, "§ 263”, en: JÄHNKE, Burkhard et al (editores), Leipziger Kommentar zum Strafgesetzbuch, $11^{\circ}$ edición, 33 entrega, Berlin - New York: Walter de Gruyter, 2000, N marginal 39, 69, 165.

${ }^{24}$ Al respecto ya TIEDEMANN, Klaus, Kartellrechtsverstö e und Strafrecht, Köln etc.: Heymanns, 1976, p. 81.

${ }^{25}$ Así, por todos, DANNECKER, Gerhard, "§ 298”, en: KINDHÄUSER, Urs et al (editores), NomosKommentar zum Strafgesetzbuch, $2^{\circ}$ edición, Baden-Baden: Nomos, 2005, No marginal 70.
} 
que prescindan de esa concreción (como ocurre, por ejemplo, con los tipos de publicidad engañosa), pero no porque se pueda poner en duda el carácter de engaño concluyente de una oferta que oculta estar basada en un acuerdo ilegítimo de precios entre competidores y, con ello, sugiere estar basada en el libre juego de la oferta y la demanda. ${ }^{26}$

Podría objetarse ahora que, sin perjuicio del indudable carácter engañoso de las ofertas que ocultan sus condiciones subyacentes, en estos casos, a diferencia de lo que ocurre, por ejemplo, con los casos de difusión de rumores falsos, no sería el engaño concluyente lo que da lugar a la alteración del precio natural de los productos o servicios, sino que el acuerdo colusorio mismo sería el que directamente provoca ese efecto. La objeción pasaría por alto, sin embargo, que, a menos que se estuviera frente a un oligopolio perfecto y respecto de bienes y servicios de demanda absolutamente inelástica, el engaño es un componente esencial para que los destinatarios de la oferta estén dispuestos a aceptarla en sus términos $\mathrm{y}$, de ese modo y recién entonces, se forme efectivamente el precio del producto o servicio. En efecto, la experiencia práctica demuestra que el público reacciona cuando se entera de prácticas colusorias concretas, lo que se expresa también en decisiones de dejar de comprar a los implicados y preferir alternativas. ${ }^{27}$ En ese sentido, el engaño concluyente en los términos expuestos es - al menos también - un medio fraudulento "por" el cual se puede conseguir alterar el precio natural de los productos o servicios.

Consecuentemente, incluso aunque se aceptara, contra la historia fidedigna y el contexto del art. 285, que éste exige como específico medio fraudulento la realización de una conducta engañosa, las conductas de colusión de precios satisfarían sin dificultades esa eventual exigencia.

\section{2. ¿Argumento a contrario a partir de la posterior legislación penal especial?}

Se podría objetar contra lo que se ha venido diciendo que si efectivamente el art. 285 fuera aplicable a los casos de colusión de precios no habría sido necesario que el legislador se

\footnotetext{
${ }^{26}$ No parece verlo así, en cambio, la literatura española, que, por lo mismo y como sería fácil de predecir, apenas logra dar con algún ejemplo (mucho menos con alguno útil) de ejecución engañosa del delito del art. 284 de su Código: SUÁREZ GONZÁLEZ, Carlos, "Difusión de noticias falsas, empleo de violencia, amenaza o engaño, o utilización de información privilegiada para alterar los precios de mercado", en: DEL ROSAL BLASCO, Bernardo (director), Delitos relativos a la propiedad industrial, al mercado y a los consumidores, Madrid: Consejo General del Poder Judicial, 1997, pp. 11-34, p. 23; CRUZ BLANCA, María José, “Art. 284", en: COBO DEL ROSAL, Manuel (director), Comentarios al Código Penal, T. IX, Madrid: Edersa, 2005, pp. 301-334, pp. 323 y ss.; BRAGE CENDÁN, Santiago, Los delitos de alteración de precios, Granada: Comares, 2001, pp. 220 y ss.; ÍÑIGO CORROZA, Elena, "La relevancia del fraude en los delitos de competencia", en: SILVA SÁNCHEZ, Jesús (director), ¿Libertad económica o fraudes punibles?, Madrid Barcelona: Marcial Pons, 2003, pp. 283-305, p. 294 (coherentemente considera que es una reiteración inútil), no obstante que desde el año 1971 el derecho español trata explícitamente la hipótesis de engaño separada de la de divulgación de rumores falsos (recién con la Ley N $\mathrm{N}^{\mathrm{0}}$ /2010 de 22 de junio, la hipótesis de divulgación de noticias o rumores falsos y la de engaño pasan a referirse a objetos distintos: la primera se refiere ahora exclusivamente a la cotización de valores o instrumentos financieros) y que en general todos los autores consienten en que el término tiene el mismo alcance que el que se le asigna en la estafa. Todo esto sólo se explica por el escaso desarrollo conceptual del engaño concluyente (también en sede de estafa) en España.

27 La indignación ciudadana que, por ejemplo, provocó la revelación del mencionado "caso farmacias" es elocuente al respecto.
} 
Polít. crim. Vol. 7, № 13 (Julio 2012), Art. 4, pp. 147 - 167.

[http://www.politicacriminal.cl/Vol_07/n_13/Vol7N13A4.pdf]

ocupara de las conductas contrarias a la libre competencia mediante una legislación penal especial, concretamente a través de los tipos penales en la Ley $\mathrm{N}^{\circ} 13.305$, de 6 de abril de 1959, y luego en el todavía vigente DL $\mathrm{N}^{\mathrm{o}} 211$, de 22 de diciembre de 1973, disposiciones que, sin duda, son bastante más explícitas que el viejo art. 285 .

Recuérdese al respecto que el inciso primero del art. 173 de la Ley $\mathrm{N}^{\circ} 13.305$ rezaba:

“Todo acto o convención que tienda a impedir la libre competencia dentro del país, sea mediante convenios de fijación de precios o repartos de cuotas de producción, transporte o de distribución, o de zonas de mercado; sea mediante acuerdos, negociaciones o asociaciones para obtener reducciones o paralizaciones de producción; sea mediante la distribución exclusiva, hecha por una sola persona o sociedad, de varios productores del mismo artículo específico, o por medio de cualquier otro arbitrio que tenga por finalidad eliminar la libre competencia, será penado con presidio menor en cualquiera de sus grados y con multa de uno por ciento al diez por ciento del capital en giro de los autores" 28 .

En tanto que el art. $1^{\circ}$ original del DL N 211 disponía:

"El que ejecute o celebre, individual o colectivamente, cualquier hecho, acto o convención que tienda a impedir la libre competencia dentro del país en las actividades económicas, tanto en las de carácter interno como en las relativas al comercio exterior, será penado con presidio menor en cualquiera de sus grados.

"Cuando el delito incida en artículos o servicios esenciales, tales como los correspondientes a alimentación, vestuario, vivienda, medicina o salud, la pena se aumentará en un grado" 29 .

Extraer, sin embargo, conclusiones sobre los alcances de un precepto del Código penal exclusivamente a partir de la existencia de esta actividad legislativa implicaría desconocer por completo las prácticas del legislador chileno. Desde luego no habría sido ni la primera ni la última vez que se legislara sobre materias ya tratadas en el Código, sin derogar al mismo tiempo las disposiciones vigentes pertinentes. Por sólo mencionar un par de ejemplos puntuales, piénsese en las disposiciones sobre atentados contra la autoridad y su relación con las disposiciones de la Ley No 12.927, de Seguridad del Estado, y de la Ley No 18.314 , sobre conductas terroristas; o en las viejas disposiciones sobre canciones, folletos y

\footnotetext{
${ }^{28}$ Derogado por el artículo quinto transitorio del DL N 211 , de 1973.

${ }^{29}$ Recuérdese, además, el art. $2^{\circ}$ original, en particular su letra d): "Para los efectos previstos en el artículo anterior se considerarán, entre otros, como hechos, actos o convenciones que tienden a impedir la libre competencia, los siguientes: a) Los que se refieran a la producción, tales como el reparto de cuotas, reducciones o paralizaciones de ellas; b) Los que se refieran al transporte; c) Los que se refieran al comercio o distribución, sea mayorista o al detalle, tales como el reparto de cuotas o la asignación de zonas de mercado o la distribución exclusiva, por una sola persona o entidad, de un mismo artículo de varios productores; $d$ ) Los que se refieran a la determinación de los precios de bienes y servicios, como acuerdos o imposición de los mismos a otros; e) Los que se refieran a la libertad de trabajo o a la libertad de los trabajadores para organizarse, reunirse, o negociar colectivamente, como los acuerdos o actos de empresarios, sindicatos u otros grupos o asociaciones, tendientes a limitar o entorpecer el libre curso de negociaciones colectivas dentro de cada empresa o los que impidan o entraben el legítimo acceso a una actividad o trabajo, y f) En general, cualquier otro arbitrio que tenga por finalidad eliminar, restringir o entorpecer la libre competencia".
} 
escritos contrarios a las buenas costumbres y las sucesivas leyes sobre "abusos de publicidad" (superadas luego por la Ley de de libertad de información) y calificación cinematográfica, que abordaron el problema de la pornografía; o en materia de comercio, la hipótesis de difusión de noticias falsas o tendenciosas del propio art. 285 y las disposiciones que al respecto contenía el ya derogado DL No 280, de 1974, sobre "delito económico"30 y sigue conteniendo la Ley N ${ }^{0} 12.927$, sobre Seguridad del Estado, ${ }^{31}$ entre muchos otros ejemplos. Por lo mismo, ni la Ley $\mathrm{N}^{\mathrm{o}} 13.305$ ni el DL $\mathrm{N}^{\mathrm{o}} 211$ pueden constituir argumento útil a la hora de determinar los alcances del art. 285, los que sólo pueden determinarse a partir de su propio tenor literal y de su historia fidedigna, con las conclusiones a las que se ha arribado más arriba.

Por otra parte, en la medida en que ninguno de estos cuerpos normativos derogó el art. 285, lo más que se puede constatar es que durante un tiempo más o menos prolongado se dio una superposición al menos parcial de regulaciones penales sobre prácticas contrarias a la libre competencia, que debía ser resuelta conforme a los principios generalmente aceptados en materia de concursos aparentes de leyes, probablemente en favor de las disposiciones de la ley especial. Una vez superada, sin embargo, esa superposición al derogarse las disposiciones penales del DL $\mathrm{N}^{\mathrm{o}} 211$ mediante la Ley $\mathrm{N}^{\circ} 19.911$, de 14 de noviembre de 2003, la materia volvió a estar íntegramente cubierta por el viejo art. 285, en la medida, naturalmente, de los alcances de este último.

Podría argüirse que las leyes especiales derogaron tácitamente, al menos de un modo parcial, el art. 285, pero con ello se pasaría por alto que los efectos de tales "derogaciones" son provisorios y están supeditados a la vigencia de la norma posterior incompatible con la anterior, de modo que si decae la vigencia de la norma posterior, la anterior no derogada expresamente es la que rige el caso. ${ }^{32}$ Lo contrario implicaría, por ejemplo, que luego de haberse introducido en el Código penal la figura de "femicidio", que naturalmente ha desplazado a los delitos de parricidio y homicidio, esto es, que los ha "derogado" tácita y parcialmente, si en el futuro se derogara la figura, habría que empezar a considerar atípicos los asesinatos de mujeres hoy constitutivos de femicidio $(i)$. $\mathrm{O}$, en el ejemplo real propuesto por Bascuñán Rodríguez, implicaría sostener que desde el 4 de junio de 2001 son atípicas en Chile las injurias y calumnias cometidas a través de un medio de comunicación social, toda vez que ese día entró en vigencia la Ley $N^{\circ}$ 19.733, que derogó expresamente la Ley

\footnotetext{
${ }^{30} \mathrm{E} 1$ art. 11 del DL No 280 sancionaba al que "difundiere noticias falsas o tendenciosas, realizare operaciones ficticias, simulare actos o contratos, o utilizare cualquier otro medio fraudulento para alterar la normalidad del abastecimiento o los precios de los artículos esenciales, la estabilidad de la moneda, de los valores o efectos públicos negociados en las bolsas de comercio, o del régimen económico nacional".

${ }^{31}$ Cuyo art. $4^{\circ}$ letra g) dispone: "Los que propaguen de palabra o por escrito o por cualquier otro medio en el interior, o envíen al exterior, noticias o informaciones tendenciosas o falsas destinadas a destruir el régimen republicano y democrático de Gobierno, o a perturbar el orden constitucional, la seguridad del país, el régimen económico o monetario, la normalidad de los precios, la estabilidad de los valores y efectos públicos y el abastecimiento de las poblaciones, y los chilenos que, encontrándose fuera del país, divulguen en el exterior tales noticias".

${ }^{32}$ Con razón ha hecho notar BASCUÑÁN RODRÍGUEZ, Antonio, "Sobre la distinción entre derogación expresa y derogación tácita”, Anuario de Filosofía Jurídica y Social, 2000, pp. 227-261, que la 1lamada derogación tácita no es más que un criterio de solución de conflictos de normas (pp. 236 y ss.) y que, en cuanto tal, debe tener efectos provisorios (pp. 239 y ss., haciéndose cargo de la doctrina contraria imperante en el derecho civil).
} 
$\mathrm{N}^{\mathrm{o}} 16.643$ sobre abusos de publicidad, la que a su vez, casi cuarenta años antes, había "derogado" tácita y parcialmente las disposiciones pertinentes del Código penal. ${ }^{33}$

Por lo mismo no puede extrañar que en la literatura especializada nadie haya sugerido siquiera, ni aun bajo la vigencia de las disposiciones penales de las leyes especiales antimonopolios, que el art. 285 hubiera perdido su vigencia, ${ }^{34}$ ni que ahora, derogadas dichas disposiciones, se recuerde precisamente que en el Código penal subsisten normas sobre prácticas contrarias a la libre competencia. ${ }^{35}$

Detrás de esta conclusión, que además de teóricamente correcta es sobre todo expresión de elemental sentido común, subyace también el reconocimiento de la radical diferencia institucional existente entre la derogación expresa y la llamada "derogación" tácita, en el sentido de que sólo en la primera se expresa inequívocamente la voluntad política del legislador, único órgano competente para ello, de expulsar una determinada norma del ordenamiento jurídico. ${ }^{36}$ En todo lo demás, salvedad hecha exclusivamente por la labor del Tribunal Constitucional en razón de jerarquía normativa (primacía constitucional), al juez sólo le cabe interpretar y conciliar conforme a ciertos criterios reconocidos las distintas manifestaciones legislativas, en algunos casos excluyendo la aplicación de alguna, pero sin que pueda negar la pertenencia al sistema de normas formalmente vigentes.

De ahí que, con razón, se deba negar en principio la posibilidad en nuestro derecho, particularmente en nuestro derecho penal, de la llamada "derogación orgánica" ${ }^{37}$ cuestión que, sin embargo, sirve de pretexto para revisar siquiera someramente la corrección de una afirmación extendida en orden a que en la Ley $\mathrm{N}^{\circ}$ 19.911, que derogó las disposiciones penales del DL $\mathrm{N}^{\mathrm{o}} 211$, se expresaba la clara voluntad política de descriminalizar el conjunto de las conductas contrarias a la libre competencia ${ }^{38}$ entre ellas, específica y deliberadamente, las colusiones de precios que constituyen el objeto de este trabajo.

Al margen de que el legislador no siempre logra plasmar en la ley lo que pretendidamente persigue y de que el juez está vinculado sólo a la ley y no a las supuestas intenciones del

\footnotetext{
${ }^{33}$ BASCUÑÁN RODRÍGUEZ, "Sobre la distinción", cit. nota nº 31, p. 245 con nota 18.

${ }^{34}$ Ténganse en cuenta las explicaciones de ETCHEBERRY, Derecho penal, cit. nota $n^{\circ} 14$, pp. 280 y ss.; y las de LABATUT, Derecho penal, cit. nota n ${ }^{\circ} 13$, p. 107.

${ }_{35}$ Así, por ejemplo, VALDÉS, Domingo, Libre competencia y monopolio, Santiago: Editorial Jurídica de Chile, 2006, pp. 225 y ss.

${ }^{36}$ Cfr. BASCUÑ̂́N RODRÍGUEZ, "Sobre la distinción", cit. nota no 31, pp. 230 y ss.

${ }^{37}$ Al respecto BASCUÑÁN RODRÍGUEZ, "Sobre la distinción”, cit. nota no 31, pp. 255 y ss. En p. 259 se lee: "si la ley de reforma contempla reglas sobre sus efectos derogatorios, y dentro de esas reglas no se encuentra una disposición derogatoria por razón de materia, debe entenderse excluida la admisibilidad de la derogación orgánica. Es prerrogativa del legislador decidir cuál sea la carga de trabajo argumentativo del juez en la justificación de sus decisiones".

${ }^{38}$ Es lo que, en buena medida, se expresa en los motivos de algunas de las mociones parlamentarias en actual tramitación que persiguen introducir tipos penales referidos específica y explícitamente a la colusión de precios, como es el caso de las de los Boletines $\mathrm{N}^{\circ}$ 6454-07 del Senado (véase la moción de 8 de abril de 2009, p. 2; y el Primer Informe de la Comisión de Constitución, Legislación, Justicia y Reglamento, de 3 de agosto de 2009, especialmente p. 3 ss.) y No 6438-03 de la Cámara (véase moción de 2 de abril de 2009, p. 1 s.; el Informe de la Comisión de Economía, Fomento y Desarrollo, de 17 de diciembre de 2009, p. 2 ss.; y la Indicación Sustitutiva de la Presidenta de la República, Mensaje No 479-357, de 10 de junio de 2009, p. 2 s.).
} 
legislador, en este caso incluso puede ponerse en duda que detrás de la derogación de las disposiciones en cuestión estuviera la "clara decisión político-criminal" de descriminalizar también la colusión de precios. En efecto, si se miran con detenimiento las razones esgrimidas para la derogación, éstas en rigor tienen que ver con los defectos manifiestos de la tipificación del DL $\mathrm{N}^{\mathrm{o}} 211$, y en ningún caso con una valoración de fondo sobre el merecimiento y la necesidad de pena de la conducta específica de colusión de precios. Así, en el Mensaje del Ejecutivo (Boletín No 2944-03) se lee lo siguiente:

"Todo tipo penal debe describir las conductas que sanciona de manera precisa, de forma que los sujetos a los cuales se dirige la norma tengan la certeza de aquello que está prohibido por el legislador.

"Sin embargo, el escenario actual en el que se desenvuelven los agentes económicos es complejo, por lo que es importante no introducir reglas que señalen per se las conductas que constituyen atentados en contra de la libre competencia. La experiencia mundial indica que hoy cada caso debe ser estudiado en su propio mérito, de acuerdo con sus complejidades y particularidades. Por estos motivos, resulta aconsejable mantener una norma amplia con ejemplos básicos, para que los integrantes del organismo encargados de conocer las causas decidan, de acuerdo al caso concreto, qué conducta constituye un atentado a la libre competencia.

"Sin embargo, este enfoque es incompatible con la existencia de una figura penal, en la cual la especificación del tipo es un requisito ineludible, so pena de vulnerar la garantía constitucional establecida en el inciso final del número 3 del artículo 19 de nuestra Constitución".

"Como contrapartida a la eliminación del carácter penal, que rara vez ha dado paso a la acción penal y se estima que no ha logrado disuadir las conductas contra la libre competencia, se propone aumentar las multas y hacer responsables solidariamente de su pago a los directores, gerentes o administradores de las empresas que incurrieren en ellas.

"De esta forma, estimamos que la eliminación del carácter penal, lejos de sugerir un ablandamiento frente a las violaciones a esta ley, va a disuadir en forma más eficaz a los potenciales infractores". ${ }^{39}$

Como se puede apreciar, al margen de la evaluación de la escasa aplicación práctica del tipo en cuestión, la objeción contra su subsistencia tenía que ver con la enorme indeterminación del tipo del art. $1^{\circ}$, que se refería a "cualquier hecho, acto o convención que tienda a impedir la libre competencia dentro del país en las actividades económicas", rematado por la cláusula general de la letra f) del art. $2^{\circ}$, que consideraba típico, en general, "cualquier otro arbitrio que tenga por finalidad eliminar, restringir o entorpecer la libre competencia".

\footnotetext{
${ }^{39}$ Mensaje, de 17 de mayo de 2002, p. 10. Estas ideas se mantuvieron en general a lo largo de toda la tramitación, agregándose ocasionalmente la idea de que los tipos en cuestión constituían una "ley penal en blanco" (por ejemplo, entre muchas otras ocasiones, Primer Informe de la Comisión de Economía del Senado, de 13 de agosto de 2002, p. 6).
} 
Desde un punto de vista penal interesa destacar que el tipo en cuestión, al margen de que la práctica administrativa pudo y puede sugerir otra cosa, era un delito de mera actividad, esto es, que no requería la producción de ninguna forma de resultado, en tanto que, por el otro lado, apenas precisaba los alcances de la conducta típica, salvo algunas pocas especificaciones en el art. $2^{\circ}$ (reparto de cuotas, asignación de zonas de mercado o de distribución exclusiva, acuerdos o imposición de los mismos, fundamentalmente), porque ciertamente no podía considerarse determinado un tipo penal que, por ejemplo, se refería genéricamente a conductas contrarias a la libre competencia "que se refieran al transporte" ${ }^{40}$ Nótese además que no era en absoluto relevante que las conductas en cuestión se desarrollaran clandestinamente o mediando medios ilícitos diversos de los que definen la propia disciplina antimonopolios, dando lugar a lo que se da en llamar significativamente "tipo universal de monopolio" 41 que, por su amplitud, permite un desarrollo jurisprudencial dinámico en sede administrativa.

Esto lo ve con toda claridad el Mensaje, como también ve que se trata de un esquema incompatible con principios básicos del derecho penal, de modo que desde esa perspectiva la supresión puede considerarse todo un acierto.

Al mismo tiempo debería ser claro, sin embargo, que con esto el legislador no ha dicho absolutamente nada respecto del merecimiento y necesidad de pena del conjunto de las posibles prácticas contrarias a la libre competencia, en particular de aquéllas respecto de las cuales no rigen las razones que militaban contra el art. $1^{\circ}$ del DL $\mathrm{N}^{\circ} 211$, cual es el caso precisamente del viejo art. 285. El art. 285 se hace cargo de una porción bien acotada del ámbito de aplicación del antiguo tipo general del DL $\mathrm{N}^{\circ} 211$. Desde luego se trata de un delito de resultado (al respecto infra 3), pero que además exige el empleo de medios fraudulentos, que, como se vio, para algunos implica engaño, exigencias que ciertamente lo hacen un tipo de alcances considerablemente más restringidos, ${ }^{42}$ muy en consonancia con el carácter fragmentario del derecho penal en relación con las demás ramas del ordenamiento jurídico: al lado de un "tipo universal" de prácticas contrarias a la libre competencia con relevancia sancionatorio-administrativa, el derecho penal sólo está llamado a intervenir frente a algunas pocas prácticas específicas, las más graves, como es el caso de la colusión de precios, a través del art. 285 del Código punitivo.

Por cierto puede discutirse si no hubiese sido preferible una solución intermedia que, en vez de suprimir in totum el tipo penal del DL No 211 y entregar íntegramente el campo de la represión de las conductas más graves contrarias a la libre competencia al art. 285, se hubiera procedido a una tipificación más exacta de las mismas en dicho cuerpo legal especial, ${ }^{43}$ que de paso hubiera permitido reflexionar sobre cuáles son las conductas más

\footnotetext{
${ }^{40}$ Una crítica a este defecto en HERNÁNDEZ, Héctor, "Perspectivas del derecho penal económico en Chile", Persona y Sociedad, Vol. XIX (2005) No 1, pp. 101-134, p. 125 y s.

${ }^{41}$ VALDÉS, Libre competencia, cit. nota $\mathrm{n}^{\mathrm{o}} 34$, pp. 241 y ss.

${ }^{42}$ Nótese, por ejemplo, que el art. 285 no abarca casos tan relevantes para el derecho de la libre competencia como son las de fusiones y concentraciones ilícitas o las de abuso de posición dominante, entre muchas otras.

${ }^{43}$ Una crítica por no haberse adoptado esa solución sin que hubiera habido un debate estrictamente penal sobre el punto en HERNÁNDEZ, "Perspectivas", cit. nota no 39, p. 126.
} 
graves en la actualidad. Pero no puede desconocerse por ello la aplicabilidad, en sus términos y dentro de sus alcances específicos, del precepto del Código.

Probablemente esta reflexión es lo que subyace en los ambiguos términos de la indicación sustitutiva del Ejecutivo a uno de los varios proyectos de ley en actual tramitación que, a propósito del "caso farmacias", buscan "reponer" el delito de colusión de precios (Boletín 6438-03), concretamente en este caso a través de la incorporación de un art. 285 bis $^{44}$ que ciertamente, también por su ubicación sistemática, tendría que desplazar nuevamente al art. 285. Afirma primero el Mensaje que "(1)a legislación en vigor no consagra un tipo penal específico para sancionar los casos en que los responsables de la gestión de los negocios se concierten para impedir, restringir o entorpecer la libre competencia, mediante un cartel o acuerdo colusorio", 45 para luego declarar que "se debe tener presente que las figuras actualmente contempladas en el Código Penal no se ajustan a cabalidad a la conducta desplegada por estos agentes, lo que impide que éstos sean eficazmente reprimidos en virtud de ese marco legal". ${ }^{46}$ Como se ve, el Ejecutivo, al margen de que hubiera sido deseable que aportara siquiera un argumento en abono de lo que sugiere, no está dispuesto a afirmar tajantemente la inaplicabilidad del art. 285, lo que probablemente se explica porque su verdadero propósito no es reponer nada, sino simplemente, de acuerdo con su política sobre libre competencia, impedir la "intromisión" de la justicia criminal y supeditar cualquier persecución penal en la materia a una decisión político-administrativa, concretamente a una querella del Fiscal Nacional Económico. ${ }^{47}$ Ahora bien, aquí no es del caso establecer ni menos enjuiciar los propósitos del Ejecutivo. Lo único relevante es que, cualesquiera que éstos fueran, no dicen nada decisivo sobre el derecho actualmente vigente.

\footnotetext{
${ }^{44}$ Del siguiente tenor: "Cuando las conductas, actos o convenciones a los que se refiere la letra a) del inciso segundo del artículo $3^{\circ}$, del decreto con fuerza de ley $\mathrm{N}^{\circ} 1$, del Ministerio de Economía, Fomento y Reconstrucción, de 2005, que fijó el texto refundido, coordinado y sistematizado del decreto ley $\mathrm{N}^{\circ} 211$, de 1973, se cometan con la finalidad de afectar actividades económicas consideradas esenciales, se castigarán con la pena de reclusión menor en su grado medio a máximo".

${ }^{45}$ Mensaje No 479-357, de 10 de junio de 2009, p. 2 (énfasis agregado).

${ }^{46}$ Mensaje $N^{\circ} 479-357$, p. 3 (énfasis agregados).

${ }^{47}$ A través de un nuevo art. 285 quater, cuyo inciso primero es del siguiente tenor: "El Ministerio Público iniciará la investigación por el delito establecido en el artículo 285 bis, únicamente previa querella del Fiscal Nacional Económico, presentada ante el juez de garantía competente, y cumpliendo con los requisitos del artículo 113 del Código Procesal Penal". Así se lee en el Mensaje, p. 5 y s.: "Otro contenido esencial del proyecto de ley que se considera imprescindible para la eficacia de la detección, cese y sanción de las conductas colusorias, es que la investigación desarrollada por el Fiscal Nacional Económico debe ser lo suficientemente contundente para ejercer la acción penal, a fin de evitar que por falta de antecedentes no se logre acreditar precisamente la conducta más grave de las que atentan contra la libre competencia. Conforme a ello, se ha considerado necesario que el Fiscal Nacional Económico sea el único sujeto dotado de la atribución de ejercer la acción penal, a través de la presentación de la querella correspondiente ante el juez de garantía competente, a efectos de asegurar que el uso de las facultades intrusivas con que ha sido dotado en el último proyecto permita recabar el máximo de pruebas idóneas para acreditar la responsabilidad penal, y decidir por consiguiente si, de acuerdo al examen pormenorizado de los elementos del tipo, ejerce la acción penal que pasa a tener por tanto el carácter de previa instancia de un particular o mixta". Los términos de la justificación son contradictorios, porque la solución propuesta limita y no amplía la persecución penal. Por cierto se podría decir, por ejemplo, que una persecución previa especializada es más eficiente, pero eso, amén de no explicitado, debería justificarse y no sólo postularse.
} 
Polít. crim. Vol. 7, № 13 (Julio 2012), Art. 4, pp. 147 - 167.

[http://www.politicacriminal.cl/Vol_07/n_13/Vol7N13A4.pdf]

En síntesis, la existencia de disposiciones penales especiales sobre la materia durante un tiempo intermedio no permite poner en duda ni la vigencia ni los alcances amplios del art. 285 del Código.

\section{Alcances del tipo: la alteración del "precio natural".}

Manifiestamente, el tipo del art. 285 constituye un delito de resultado, puesto que no basta con el empleo de los medios fraudulentos para su consumación, sino que se requiere que por esa vía se "consiguiere" alterar el precio natural de los productos o servicios. ${ }^{48}$ En consecuencia, debe resolverse en qué consiste el resultado típico "alteración del precio natural" de los productos o servicios, lo que implica por una parte dilucidar qué debe entenderse por "precio natural" y, por la otra, determinar en qué sentido éste debe haber sido alterado.

Respecto de lo primero la respuesta parece bastante clara y se encuentra expresada, como se vio, tanto en la historia fidedigna del establecimiento de la ley como en la literatura producida a su respecto: precio natural es el que resulta de la libre competencia, del libre juego de la oferta y la demanda. Así lo decía expresamente, como se recordará, el art. 362 del Código español de 1850 ("los precios naturales que resultarían de la libre concurrencia") y así se ha entendido siempre entre nosotros (al respecto supra 1).

La objeción que obviamente debe enfrentar esta concepción es que supone una situación de competencia perfecta que difícilmente se da en las economías modernas, denotando de paso una visión algo naïf sobre el funcionamiento del mercado. Podría sostenerse, entonces, que o bien no existe un "precio natural" de los productos o servicios, o bien que éste simplemente corresponde al que en concreto se cobra o se paga en una transacción particular, con la consecuencia, en ambos casos, de que nunca podrían realizarse las exigencias del tipo penal. No parece ser éste, sin embargo, un modo razonable de entender la ley, porque al margen de las imperfecciones del mercado, en tanto no se trate de precios fijados por la autoridad, siempre existe un ámbito mayor o menor de competencia susceptible de ser alterada mediante acuerdos de precios u otros medios fraudulentos y que es precisamente lo que el precepto persigue resguardar. Es lo que la doctrina española unánimemente reconoce como protección de una "libre concurrencia relativa" ${ }^{49}$ El precio natural de los productos o servicios es, en consecuencia, el precio que hubiese resultado de haberse respetado las condiciones de esa libre competencia relativa.

\footnotetext{
${ }^{48}$ Esto marca una diferencia relevante con el actual tipo español, que, como se dijo, desde la reforma de 1971 pasó a ser un delito de mera actividad con elemento subjetivo adicional que sanciona a los que intentaren alterar los precios que habrían de resultar de la libre concurrencia mediante los medios ilícitos señalados.

49 Antes del Código de 1995 MUÑOZ CONDE, Francisco, Derecho penal. Parte especial, $8^{\circ}$ edición, Valencia: Tirant lo Blanch, 1990, p. 349; BOIX, Javier, "Delitos contra la propiedad (continuación). Maquinaciones para alterar el precio de las cosas", en: VIVES ANTÓN, Tomás (coordinador), Derecho penal. Parte especial, $3^{\circ}$ edición, Valencia: Tirant lo Blanch, 1990, pp. 965-979, p. 972; con posterioridad al Código SUÁREZ GONZÁLEZ, Carlos, "Art. 284", en: RODRÍGUEZ MOURULLO, Gonzalo (director), Comentarios al Código penal, Madrid: Civitas, 1997, pp. 818-821, p. 819; QUINTERO OLIVARES, Gonzalo, "Art. 284", en: QUINTERO OLIVARES, Gonzalo (director), Comentarios a la parte especial del derecho penal, $2^{\circ}$ edición, Elcano: Aranzadi, 1999, pp. 672-675, p. 674.
} 
Esta comprensión del precio natural como precio obtenido bajo condiciones efectivas de competencia relativa determina inmediatamente el significado de la alteración típica y permite despejar ciertos malentendidos que pueden generarse a propósito de su determinación.

Habrá alteración del precio natural de un producto o servicio cada vez que el precio no se haya obtenido bajo condiciones efectivas de competencia relativa. Tomada en términos literales, esta afirmación parecería implicar la transformación del tipo penal, que manifiestamente es de resultado, en uno de mera actividad, ya que por definición el simple empleo de los medios fraudulentos, en este caso del acuerdo de precios, importaría alteración del precio natural del producto o servicio y, con ello, la consumación del delito. No es eso, sin embargo, lo que se quiere significar, porque evidentemente podrá ocurrir que por factores de diversa índole - particularmente por la falta de poder de mercado - la práctica colusoria no tuviera en concreto efectos sobre el precio, caso en el cual sólo se podría sancionar por el delito frustrado. ${ }^{50}$ Lo que importa no es, en consecuencia, el precio que se acuerda cobrar, sino el que se logra imponer en operaciones concretas. Si se puede afirmar que de no haber mediado la conducta colusoria con toda seguridad el precio del producto o servicio hubiese sido uno distinto al efectivamente cobrado al menos en una operación concreta, se dan todos los requisitos para aplicar la pena por el delito consumado.

A ese resultado contribuyen en igual medida todos los que participan en la colusión, también los que en concreto no lograron imponer el precio acordado en operaciones concretas. No es necesario que la operación con un precio alterado la verifiquen ellos mismos, basta con que hayan contribuido a la alteración del precio. Por lo mismo, es irrelevante que el acuerdo de precios se dé en un caso puntual de un modo que haga previsible que uno o más intervinientes no logren ninguna venta, por ejemplo, cuando se idea un sistema que se mantiene en el tiempo y en el que en cada nueva fijación se "favorece", alternadamente, a uno o a algunos de los supuestos competidores, fijando el resto precios menos convenientes: sin perjuicio de que en algún momento también se vean favorecidos por las mayores ventas, ya antes, al haber contribuido a la alteración del precio natural en favor de otros, incurren en el delito.

No es necesario, por las mismas razones, que se sepa con exactitud cuál habría sido "el" precio natural del producto o servicio en cuestión. ${ }^{51}$ No lo es por la sencilla razón de que el resultado típico consiste en la producción de una diferencia entre dos magnitudes (el precio resultado de la colusión y el precio natural), sin que la cuantificación de dicha diferencia sea típicamente relevante, como sí lo sería si el tipo penal requiriera perjuicio patrimonial de alguien y la pena, además, se asociara al monto de dicho prejuicio, como ocurre, por ejemplo, en materia de estafa, ${ }^{52}$ o si el tipo exigiera que la diferencia entre precios exceda de una cierta medida, como ocurre con la usura. Ciertamente la alteración del precio natural

\footnotetext{
${ }^{50}$ A menos que la ausencia de efectos sobre el precio correspondiera al conocimiento y propósitos de los agentes, caso en el cual, por falta de dolo, la conducta no sería típica ni aun a título de ejecución imperfecta.

${ }^{51}$ Yerra en este punto la sentencia, ya citada, de la Corte de Valparaíso, Gaceta de los Tribunales 1929-I, sentencia 86, pp. 428, 433.

${ }^{52}$ Salvo, por cierto, en el caso de la llamada estafa residual del art. 473, que excepcionalmente no se remite a las penas (tasadas en base al monto del perjuicio) del art. 467.
} 
Polít. crim. Vol. 7, № 13 (Julio 2012), Art. 4, pp. 147 - 167.

[http://www.politicacriminal.cl/Vol_07/n_13/Vol7N13A4.pdf]

de un producto o servicio puede irrogar un perjuicio a terceros, generalmente a los adquirentes del mismo, ${ }^{53}$ pero a todas luces no constituye una exigencia del tipo que deba cuantificarse para efectos penales (como sí podría tenerlo para efectos civiles de indemnización de perjuicios). Para el art. 285 basta con poder afirmar que el precio obtenido al menos por alguno de los intervinientes en la colusión es uno distinto del que hubiera resultado en condiciones de genuina competencia.

Por último, es sin duda evidente la tipicidad de la alteración del precio que se expresa en un precio mayor, que es, por lo demás, el caso normal. Es dudoso, sin embargo, si rige lo mismo para las eventuales alteraciones hacia la baja. Tratándose de un delito contra la libre competencia como mecanismo de formación de los precios, en principio no cabría hacer distinciones, ${ }^{54}$ aunque debe reconocerse que el punto requeriría un estudio adicional que no es posible solventar aquí.

\section{Conclusión.}

En base a lo precedentemente expuesto se puede concluir que el tipo penal del art. 285 se encuentra plenamente vigente y que es subsumible en él la conducta de quienes ofrecen productos o servicios al público ocultando que se han puesto de acuerdo con otros oferentes en cuanto al precio exigido, dando lugar de ese modo, al falsificarse la situación de libre competencia relativa supuesta en la oferta, y en la medida en que quienes se coluden tengan suficiente poder de mercado, a un precio distinto del que se hubiera formado de no haber mediado dicho acuerdo ("precio natural"). Derogadas las disposiciones penales contenidas en las leyes especiales sobre conductas contrarias a la libre competencia, el art. 285 es el único precepto actualmente aplicable a este tipo de conductas, sin perjuicio de una posible calificación conforme al art. 286.

\footnotetext{
${ }^{53}$ Así, enfáticamente, ETCHEBERRY, Derecho penal, cit. nota $n^{\circ}$ 14, p. 280: "necesariamente resultará un perjuicio, ya que en toda alteración del 'precio natural' hay quien sale perdiendo, sea el público en general, sea el contratante víctima del fraude".

${ }^{54}$ Así, por ejemplo, para el derecho español, entre otros, SUÁREZ GONZÁLEZ, "Art. 284", cit. nota $\mathrm{N}^{\circ} 48$, p. 819 .
} 
HERNÁNDEZ, Héctor, "La punibilidad de la colusión (secreta)

de precios en el derecho chileno".

\section{BIBLIOGRAFÍA}

Actas de las sesiones de la Comisión Redactora del Código penal chileno, Santiago: Imprenta de la República de Jacinto Núñez, 1873.

BAÑADOS ESPINOSA, Florencio, Código penal de la República de Chile concordado y comentado, Santiago: L.A. Lagunas, 1920.

BASCUÑÁN RODRÍGUEZ, Antonio, "Sobre la distinción entre derogación expresa y derogación tácita", Anuario de Filosofía Jurídica y Social, 2000, pp. 227-261.

BOIX, Javier, "Delitos contra la propiedad (continuación). Maquinaciones para alterar el precio de las cosas", en: VIVES ANTÓN, Tomás (coordinador), Derecho penal. Parte especial, $3^{\circ}$ edición, Valencia: Tirant lo Blanch, 1990, pp. 965-979.

BRAGE CENDÁN, Santiago, Los delitos de alteración de precios, Granada: Comares, 2001.

CRUZ BLANCA, María José, “Art. 284”, en: COBO DEL ROSAL, Manuel (director), Comentarios al Código Penal, T. IX, Madrid: Edersa, 2005, pp. 301-334.

DANNECKER, Gerhard, "§ 298”, en: KINDHÄUSER, Urs et al (editores), NomosKommentar zum Strafgesetzbuch, 20 edición, Baden-Baden: Nomos, 2005.

DEL RÍO, J. Raimundo, Derecho penal, Santiago: Nascimento, 1935.

ETCHEBERRY, Alfredo, Derecho penal, $3^{\circ}$ edición, Santiago: Editorial Jurídica de Chile, 1998.

FERNÁNDEZ, Pedro Javier, Código penal de la República de Chile esplicado y concordado, $2^{\circ}$ edición, T. II, Santiago: Imprenta Barcelona, 1900.

FRISCH, Wolfgang, "Konkludentes Täuschen", en: PAWLIK, Michael et al (editores), Festschrift für Günther Jakobs, Köln etc.: Heymanns, 2007, pp. 97-130.

FUENSALIDA, Alejandro, Concordancias i comentarios del Código penal chileno, Lima: Imprenta comercial, 1883.

HEFENDEHL, Roland, "§ 263”, en: AA. VV., Münchener Kommentar zum Strafgesetzbuch, München: Beck, 2006.

HERNÁNDEZ, Héctor, "Aproximación a la problemática de la estafa", en AA. VV., Problemas actuales de Derecho penal, Temuco: Universidad Católica de Temuco, 2003, pp. 147-190.

, "Perspectivas del derecho penal económico en Chile", Persona y Sociedad, Vol. XIX (2005) No 1, pp. 101-134.

ÍNIGO CORROZA, Elena, "La relevancia del fraude en los delitos de competencia", en: SILVA SÁNCHEZ, Jesús (director), ¿Libertad económica o fraudes punibles?, Madrid - Barcelona: Marcial Pons, 2003, pp. 283-305.

KINDHÄUSER, Urs, "§ 263”, en: KINDHÄUSER, Urs et al (editores), NomosKommentar zum Strafgesetzbuch, $2^{\circ}$ edición, Baden-Baden: Nomos, 2005.

LABATUT, Gustavo, Derecho penal, T. II, $7^{\circ}$ edición (a cargo de Julio ZENTENO), Santiago: Editorial Jurídica de Chile, 1983.

MAÑALICH, Juan Pablo, “¿Responsabilidad jurídico-penal por causaciones de menoscabo patrimonial a propósito de fallas en la construcción de inmuebles?", Política Criminal, Vol. $5 \mathrm{~N}^{\mathrm{o}} 10$ (2010), pp. 341-351.

MERA, Jorge, Fraude civil y penal. El delito de entrega fraudulenta, $2^{\circ}$ edición, Santiago: ConoSur, 1994. 
Polít. crim. Vol. 7, № 13 (Julio 2012), Art. 4, pp. 147 - 167.

[http://www.politicacriminal.cl/Vol_07/n_13/Vol7N13A4.pdf]

MUÑOZ CONDE, Francisco, Derecho penal. Parte especial, $8^{\circ}$ edición, Valencia: Tirant lo Blanch, 1990.

PACHECO, Joaquín Francisco, El Código penal concordado y comentado, $4^{0}$ edición, Madrid: Imprenta de Manuel Tello, 1870.

QUINTERO OLIVARES, Gonzalo, “Art. 284”, en: QUINTERO OLIVARES, Gonzalo (director), Comentarios a la parte especial del derecho penal, $2^{\circ}$ edición, Elcano: Aranzadi, 1999, pp. 672-675.

SUÁREZ GONZÁLEZ, Carlos, “Art. 284”, en: RODRÍGUEZ MOURULLO, Gonzalo (director), Comentarios al Código penal, Madrid: Civitas, 1997, pp. 818-821.

, "Difusión de noticias falsas, empleo de violencia, amenaza o engaño, o utilización de información privilegiada para alterar los precios de mercado", en: DEL ROSAL BLASCO, Bernardo (director), Delitos relativos a la propiedad industrial, al mercado y a los consumidores, Madrid: Consejo General del Poder Judicial, 1997, pp. 11-34.

TIEDEMANN, Klaus, Kartellrechtsverstö e und Strafrecht, Köln etc.: Heymanns, 1976. , "§ 263", en: JÄHNKE, Burkhard et al (editores), Leipziger Kommentar zum Strafgesetzbuch, $11^{\circ}$ edición, $33^{\circ}$ entrega, Berlin - New York: Walter de Gruyter, 2000.

VALDÉS, Domingo, Libre competencia y monopolio, Santiago: Editorial Jurídica de Chile, 2006.

VERA, Robustiano, Código penal de la República de Chile comentado, Santiago: Imprenta de P. Cadot, 1883. 